\title{
DIGITALCOMMONS
}

@WAYNESTATE-

Wayne State University

4-1-2019

\section{Strategies to Increase Athletes' Transformational Leadership Behaviors During Strength and Conditioning Sessions}

\author{
Valerie Smith \\ Wayne State University \\ E. Whitney G. Moore \\ Wayne State University, whitneymoore@wayne.edu
}

Follow this and additional works at: https://digitalcommons.wayne.edu/coe_khs

Part of the Education Commons, Kinesiology Commons, and the Sports Sciences Commons

\section{Recommended Citation}

Smith, V., \& Moore, E. W. G. (2019). Strategies to increase athletes' transformational leadership behaviors during strength and conditioning sessions. Strength and Conditioning Journal, 41(2), 31-37. DOI: 10.1519/ SSC. 0000000000000422

This Article is brought to you for free and open access by the College of Education at DigitalCommons@WayneState. It has been accepted for inclusion in Kinesiology, Health and Sport Studies by an authorized administrator of DigitalCommons@WayneState. 
Running head: BUILDING ATHLETE LEADERSHIP BEHAVIORS

1

2

3

4

5

6

Strategies to increase athletes' transformational leadership behaviors during strength and

conditioning sessions

8

9 


\section{Abstract}

11 Often, leadership is presumed to naturally result from athletic experiences. However, leadership

12 behaviors require practice. Strength and conditioning coaches (SCCs) can provide opportunities for all

13 athletes to practice transformational leadership behaviors, which can increase team cohesion and

14 performance. This article reviews athlete leadership, including leadership roles and four

15 transformational leadership behaviors (idealized influence, inspirational motivation, individualized

16 consideration, and intellectual stimulation). Then, daily strategies SCCs can incorporate into training to

17 foster athletes' transformational leadership are presented. Followed by strategies for larger, rotating

18 leadership experiences. These strategies can work with athletes across age, gender, and competitive

19 level.

20 Keywords: Coaches; Collegiate; High-school; Long-term athlete development; Sport psychology;

21 Communication and relationship development; student-athlete

22

23 
Strategies to increase athletes' transformational leadership behaviors during strength and

\section{conditioning sessions}

Strength and conditioning coaches (SCC) can increase their athletes' performance and team

27 cohesion by encouraging their athletes to assume leadership responsibilities during strength and

28 conditioning training sessions. Leadership researchers have shown that leadership is comprised of

29 multiple behaviors $(2,6,20,21)$. As with other behaviors, leadership behaviors can be cultivated and

modified $(4,30,33)$. Traditionally, leadership in sport has come from coaches and athletes with formal

31 leadership roles (9). However, recently researchers have highlighted athletes increased reliance on their

32 teammates' informal leadership $(10,19)$. Informal leaders can be defined as a person on a team who

33 does not have a formal or official leadership role (e.g., non-captains, non-starters, underclassmen) (26).

34 Therefore, although all athletes cannot have formal leadership roles (i.e., a captain), all athletes can

35 build their leadership behaviors and be informal leaders $(3,9,17,21)$. Research examining leadership has identified specific behaviors of effective leaders $(8,21,30)$. After introducing the behaviors of effective

37 leaders, ways SCCs can incorporate athlete leadership behavior development into their training

38 structure is presented.

Qualitative research with team athletes revealed their preference for athlete leadership being spread across the team, rather than reserved for a select few $(10,19,23)$. Whether formal or informal,

41 the behavior of providing leadership has been characterized as a process that influences others, and

42 involves goal attainment occurring within a group context (29). Athletes and researchers have

43 recommended that the more athletes there are who behave as leaders, the better $(10,23,27)$. Having a

44 combination of both formal and informal leaders within a team improves athlete role clarity, as well as

45 both individual and team performance (10). Having more athletes involved as informal leaders is associated with increased team cohesion as a function of increased athlete closeness and everyone

47 feeling they are a contributing member of the team (10). There are a wide variety of informal leadership 

67 informal leaders.'

roles that athletes can fill on a team. Informal leaders can provide additional motivation, instruction and feedback, as well as individual consideration and social support (10). Athletes have described these informal leaders as leading by example (e.g., the athlete who always gives $100 \%$ ), cheering on peers during difficult training sessions or competitions, and providing one on one mentorship $(2,4,10)$. Increasing athletes' leadership behaviors increases the impact of athletes as informal leaders, while also developing leadership behaviors they may use as formal leaders in the future.

These behaviors - inspirational motivation, idealized influence, and individual consideration reported in qualitative research by athletes asked to describe the behaviors of their informal leaders aligns with the theory of transformational leadership. This theory emphasizes the process through which leaders promote commitment for group goals and objectives, and transform (i.e., influence considerable change) other group members' attitudes and assumptions by providing idealized influence, inspirational motivation, individualized consideration, and intellectual stimulation $(2-4,28)$. These four behaviors can be expressed not only by those in traditional, formal leadership positions; but rather by a variety of people (3). Important to SCCs, Charbonneau and colleagues (7) found that the more University athletes perceived their coaches to use transformational leadership behaviors, the greater their intrinsic motivation and future athletic performance. These results are similar to those found in previous literature when transformational leadership was examined in military, business, and education settings $(2-4,7)$. Therefore, the focus of this paper is to illustrate how SCCs can promote the expression of these transformational behaviors by all their athletes to facilitate effective leadership by both the formal and

\section{Effective Leadership Behaviors} performance abilities), beliefs (e.g., self-esteem), and attitudes (e.g., sport enjoyment), as well as

71 motivation and performance (20). Through the relationships that effective leaders build, they motivate, 
72 assure, comfort, and support others (21). The primary leadership behaviors of informal leaders reported

73 by athletes were inspirational motivation, individualized consideration, and idealized influence (10). Inspirational motivation includes behaviors commonly role modeled by SCCs during strength

75

76

77 and conditioning training, such as providing reinforcement feedback, hustle feedback, and verbal statements intended to intensify efforts (24). Providing reinforcement feedback, includes acknowledging what an athlete is doing through verbal and nonverbal praise or positive statements. Weight room specific examples include providing reinforcement of a teammate's exercise technique ("great depth on that last squat"), improved performance ("congrats on the new PR in back squat"), or effort ("way to push yourself today"). An example of hustle feedback is a group of athletes cheering on their peers to maintain or increase their end of training hustle and quality. The importance of receiving positive and reinforcing feedback has been shown in research across disciplines and supports the goal of individuals receiving at least five positive reinforcements for every negative feedback and/or punishment they receive (25). The more reinforcement feedback individuals receive, the more effort they give, the more efficacious they feel, and their performance improves (25). Although coaches give this feedback during training $(4-21 \%$ of their feedback during training $(24))$, so can teammates. The more athletes who are informal leaders, the more positive reinforcing feedback each athlete has the potential to receive, which may help more athletes experience the recommended ratio of at least five positive reinforcements for each negative reinforcement and/or punishment.

Individualized consideration includes informal peer to peer mentorship. In strength and conditioning training, athletes may train together across age/grade levels, starter/non-starter roles, sport positions, and even sport. This flexibility can increase the opportunities to match athletes based on other characteristics that can promote quality peer to peer mentorship within and outside of training. Athletes also express individualized consideration through teaching each other when they provide 
instructional and technical feedback. In fact, athletes have reported one benefit of having more informal athlete leaders is experiencing "more one on one work and individual help" p. 360 (10). Idealized influence includes role modeling and leading by example. Holmes, McNeil, and Adorna (19) found athletes desire leaders who provide role modeling and lead by example. In addition to SCCS being role models, SCCs can also promote athletes practicing this leadership behavior. Role models are individuals who peers look to for guidance, support, and advice (1). Athletes who stay after a training session to ensure that the weight room is put back according to the SCCs' expectations are leading by example, and modeling a behavior for others to follow. A role modeling example specific to the strength and conditioning context is an athlete taking the time to demonstrate how to do an exercise with correct technique to provide a visual role model for another athlete. The peer athlete in these two example situations can be so influential because the peer is either currently going through the same experience, or has recently gone through that experience (12). The commonality of the experience and being at the same relative level (i.e., peer vs coach) increases the saliency of peer role modeling $(12,34)$. In other words, compared to the SCC, the peer role model is more relatable and similar to the athlete. Knowing that someone similar to you finds the training difficult currently or in the recent past also helps to normalize the experience (12). This similarity helps to reinforce that the mentee athlete will be able to complete the training challenge and reap its benefits. The more similar role models are to the mentee athletes (i.e., other athletes versus SCCs), the more effective the idealized influence (31).

The above three transformational leadership behaviors can be practiced within or outside of a training setting. However, compared to sport, there are aspects unique to strength and conditioning training sessions that provide opportunities for SCCs to promote these leadership behaviors among their athletes. First, strength and conditioning training exercises are primarily performed by individuals, rather than as the whole team together. For example, the individual completing squats is not dependent on others to perform the exercise, whereas most team sport drills incorporate at least one other athlete 
whose performance affects the successful completion of the drill. This is a noteworthy distinction, because it means peers are available to provide support in a variety of ways (e.g. spotting, motivational feedback, and reinforcement). It also means that SCC's can provide adaptations that personalize athletes' training, as well as incorporate athletes who may be unable to train during sport practice due to an injury. A further benefit is that SCC's can organize training partners/groups across characteristics that often divide athletes during sport practice into consistent subgroups (e.g., starter status, position, or grade/seniority). Second, SCCs work with every athlete regardless of sport position, health, starter status, and grade/seniority. Third, the SCC's training space is often more compact than where the athletes practice their sport. Being in a more compact space also enables the SCC to interact more directly and personally with individual athletes during every training session. This last aspect in particular can increase SSCs ability to create a relationship with each athlete on the team unlike other coaches. As relationships are the building blocks to organize activities for achieving goals (21), SCCs seem to have a setting uniquely conducive to increasing the leadership behaviors of all athletes. As with other aspects of athlete training, SCCs and the sport coaching staff can collaborate regarding athletes' leadership experiences across sport and strength and conditioning sessions. In addition to providing cohesiveness of messaging across training contexts for the athletes, SCCs may be able to provide unique insight to the sport coaches into which athletes are prepared for different levels of leadership responsibility based upon the athletes' responses to the different informal leadership behavior opportunities presented during the SCCs' training sessions.

Below we present specific examples of ways to integrate leadership behavior practice into the existing strength and conditioning training structure. We have divided these approaches into two categories: those that provide every athlete with leadership opportunities during every training session and those that provide for rotation of leadership responsibilities so that the athletes have slightly larger leadership experiences regularly, but not daily. 


\section{Leadership Opportunities for Every Training Session}

There are leadership behaviors that athletes can do every day to be more effective informal leaders. Just as with any other skill, the more consistently and frequently leadership behaviors are practiced, the more automatic they become (13). As with other skills, individuals need to build on the fundamentals that can be practiced daily during training sessions. These informal, daily leadership experiences set the foundation for athletes to potentially take on more formal leadership roles. Below are examples of opportunities SCCs can provide athletes during training sessions to practice the skills and vocabulary of leadership. Although these behaviors may seem inherent to training sessions, the athletes' behaviors need to be explicitly promoted and emphasized by the SCC within these existing strength and conditioning training session structures to see the greatest effect (5).

\section{Individualized Consideration: Give a training partner form feedback}

Athletes can learn how to give individualized consideration through providing constructive technical/instructional feedback to their training partners. Athletes are often taught the key cues for any movement they are doing during training. These same athletes, including youth, can also be trained that it is their responsibility to give form feedback to their training partner using those same key cues. Even 10-year-old athletes can tell if their training partner does squats with their chest up, heels down, and knees above (not past) their toes. To make it easier to give feedback, we can provide them with the cue words to use. This means everyone is using the same language and understands their partner's feedback cues. This also helps ensure that the feedback is being given in a constructive (i.e., positive and informative) manner; rather than providing feedback in a destructive (e.g., teasing or negative) manner, which would be building poor leadership behavior habits. SCCs can explicitly build a culture of athletes giving feedback to training partners by specifically telling athletes one of their training responsibilities is to help their teammates improve and avoid injury due to form errors. Plus, SCCs can reinforce athletes' ability to give feedback by not always correcting the training partner for the athlete. Rather, the SCC can 
ask the training partner, "How does their squat look? Any feedback for them?" This creates an opportunity to build the athletes' ability to do squats, plus their partner's ability to confidently and effectively communicate with their teammate (an important skill in and out of sport).

\section{Inspirational Motivation: Give positive feedback to a peer}

SCCs can also provide athletes opportunities to learn how to give and receive positive, constructive feedback, which is an inspirational motivation behavior. This includes teaching athletes when it is appropriate to give feedback - not while coach is talking or necessarily in the middle of the lift - and how to give positive or encouraging feedback. How and when to give positive or encouraging feedback can be trained and reinforced with structured practice opportunities. A highly structured option is to stop at the end of an activity (e.g., right before a water break or transition) and ask athletes

to share a positive accomplishment of a peer. This accomplishment could include high effort, improvement on an exercise, executing an exercise technique well, or trying again after a mistake. Taking these 30 second breaks to ask athletes to publicly praise their peers builds their awareness of what their peers are doing, as well as their vocabulary for praising each other. Another strategy that provides a cue for athletes to praise each other and provides a standard way of giving that praise is to have a universal signal to highlight when a peer has performed a personal record. For example, having a bell that athletes ring when they have just achieved a personal record signals this accomplishment to the rest of their peers and triggers a common, and potentially pre-determined, form of praise (e.g., highfives, cheers). Again, this approach provides a structured cue to assist the athletes in knowing when a peer has just achieved an improvement, and then publicly recognize that improvement. However, this is less structured than pausing between activities to ask for athletes to share praise for their peers. By incorporating these different levels of structured feedback practice into training sessions, SCCs are giving athletes opportunities to build the skills of recognizing their peers' effort and improvement, finding an appropriate way of expressing positive reinforcement feedback (e.g., high five, congratulatory 
191 words, cheer), and building their comfort as giving reinforcement feedback becomes an automatic 192 behavior.

Idealized Influence: Do an exercise with a peer (role model)

There are a variety of ways that more experienced athletes can be role models to more novice athletes in strength and conditioning sessions. When SCCs provide specific opportunities for role modeling by athletes, there are two potential benefits: a) the novice athletes may become more engaged and influenced by the more experienced athletes and b) the more experienced athletes build their ability to not just lead by example (intentionally or not), but behave as a role model. Although some athletes may spontaneously lead by example, being put into the role model position by the SCC may provide the structured experience some athletes need to develop their idealized influence leadership behavior. One approach is to ask the more experienced athletes to describe their process for learning an exercise that may be new or revising their technique. For example, when learning a technical exercise, such as the power clean, athletes may progress through learning with a PVC pipe or broom stick, then an unweighted Olympic bar, and finally a weighted Olympic bar. Athletes who have gone through these steps can reinforce to their peers why it is important to take these steps seriously to learn proper form (or revise previously learned form). Some coaches send this message implicitly by having all

207 athletes, regardless of experience, go through these training form progressions to reinforce to everyone 208 the importance of proper form. Another approach can be to have athletes of different abilities or 209 experience partner together, and tell the more advanced athlete it is their responsibility to assist their 210 partner in overcoming the day's training challenge. An example of how to implement this approach is

211 with athletes doing box jumps at a new height. Often, the greatest barrier to athletes' box jump 212 performance is their fear of not making the jump. Hearing from a peer that the box jump is less scary or 213 difficult than it looks can help reduce the athletes' fear more than hearing the same comment from their 214 coach. In addition to hearing a peer's experience with box jumps, seeing that peer successfully complete 
215 the same box jump can further increase the athletes' belief that they too can safely execute the box 216 jump.

The gap between the above daily, informal leadership, and formal leadership roles can be bridged with rotating, temporary leadership roles. By recognizing athletes' strengths, SCCs can identify rotating leadership roles that most align with athletes' strongest leadership behaviors, and which roles may provide a greater challenge. For example, athletes strongest in individualized consideration in oneon-one or small groups may transition easily into opportunities for a) guiding a new or developing

223 athlete or b) leading small group discussion on what went well in training and what could be improved.

224 Whereas the same athlete may feel more challenged when demonstrating an exercise in front of the full 225 team or leading the team's warmup. It is important to allow athletes room to explore these different 226 leadership behaviors and roles. SCCs can provide leadership challenges. For example, athletes who are 227 comfortable in one situation (small groups) can benefit from the challenge experience of being in a 228 leadership role they find less comfortable (large group or demonstrating). Just as SCCs try to set athletes 229 up for success in training, SCCs do the same for athletes as leaders. This gives athletes the opportunity 230 to grow as a leader and person.

\section{Idealized Influence: Demonstrate an exercise}

The benefits of role modeling by a peer (e.g., model more similar to the athletes) in a one-onone or small group situation, also hold when the role modeling is done in front of a large group, such as

234 the team. When choosing athletes to demonstrate an exercise in front of the team, coaches may think 235 of the athletes with the best, most perfect form. An unfortunate side-effect of this approach is there 236 may be very little variability in who coaches ask to demonstrate exercises; as the same, few, top athletes

237 keep being asked to demonstrate. However, if coaches can accept a good though perhaps not perfect 238 demonstration, then the athletes who could demonstrate an exercise increases. Any imperfection in an 
athlete's demonstration may be used by the coach as an opportunity to provide some additional form instruction to all the athletes. Coaches may be surprised by who is confident enough to volunteer to demonstrate. An additional benefit of asking for volunteers is coaches get to select from athletes who

242 are confident and want to demonstrate. This can result in the flexible athletes being more likely to

243 demonstrate dynamic stretching techniques, while the more agile athletes volunteer for footwork and 244 agility exercises, and the powerful athletes volunteer for the plyometric and Olympic-style lifts. This 245 gives a larger individualized influence opportunity to athletes who may not be comfortable enough to 246 lead part of a workout or a training group.

There are additional benefits to asking for demonstration volunteers. Increasing the number of

248 athletes who demonstrate exercises also reduces the appearance of favoritism by coaches. The 249 demonstrating athlete(s) can also receive praise for their demonstration from their peers and coaches, 250 reinforcing their exercise competence and their choice to role model the exercise technique. These are 251 additional benefits that can increase athletes' confidence in their abilities. Selecting our exercise

252 demonstrators by simply asking, "Who wants to demonstrate " may increase the number of

253 different athletes demonstrating, provide them an opportunity to practice a leadership behavior, and 254 build their confidence.

\section{Individual Consideration: Athlete-led segment}

Athletes can also build their ability to provide individual consideration to their peers as a large

257 group by having rotating experiences leading segments of training. These can be "pre-scripted"

258 segments that have set routines, such as warmup/cooldown, or "unscripted" segments the athlete co259 leaders are responsible for developing and leading the team through. An example of the first approach is 260 to have different athletes be responsible for leading the team through their regular warmup and/or 261 cooldown routine. Once the athletes have learned the routine from the SCC, the volunteer or assigned 262 leaders who take the team through the routine can be regularly rotated (e.g., weekly). The athlete 
leaders may accidentally change the order of a stretch or two, or need to be reminded to include a stretch. This provides them valuable larger group leadership experience in a safe, low-stakes setting. An example of the second, "unscripted" approach is to select one or more athletes to led the training activity for the last 10 minutes of the subsequent training session. They are responsible for planning the last activity (e.g., game, workout, or extra running) the team will do to finish off their training session. At the next training session, the athletes explain the activity, implement it, and cleanup after it. This approach has multiple benefits. One, it enables coaches to see what aspects of training the athletes are enjoying and/or wanting to work on. Two, the athletes are leading an activity of their own creation rather than mimicking or following the SCCs script, as they are with the warmup/cooldown routine. Third, it gives coaches the opportunity to provide athletes with feedback afterwards about their leadership behaviors during the 10-minute activity. Both of these approaches also provide athletes the opportunity to develop their ability to lead with at least one partner (co-leader). This provides greater learning for the athletes as they develop their leadership behaviors for a large group, and helps the athletes become comfortable with their own, personal leadership style.

\section{Inspirational Motivation: Session Reflection}

In addition to motivating individuals, athletes can also motivate their whole team, and help steer or guide the team in a positive direction. An opportunity for athletes to practice this type of inspirational motivation is by leading the session reflection. To help athletes leave the training session focused on the positives that came out of training, athletes can conduct a quick (i.e., less than 5 minutes) end of session reflection. The chosen athlete leads the team through the session reflection, which includes the following three components. First, athletes share a quick statement about how they each did at reaching one of their goals for that session. Second, coaches quickly share their perspective of how the training session went. These two components can occur during the end cooldown and/or stretching segment of training. Third, coaches and athletes circle up and put their hands in the middle. 
287 Then, the chosen athlete for that day gives a chant or saying (e.g. team, work hard, name of school) for everyone to repeat before breaking the circle and leaving the training session. Given how busy both coaches and athletes are, these short, immediate reflections have two primary benefits: a) both athletes and coaches get time to reflect on how the individuals, whole team, and coaches performed, and b) it

291 allows preparation for what is to come (e.g., future training sessions, team practices, or competitions).

292 Expert coaches have reported reflective practice as useful for their own self-improvement $(11,15-17)$. In

293 addition, researchers have found reflective practices to be beneficial for both coaches and athletes to 294 assess and improve their training $(14,18,22,33)$.

\section{Conclusion}

The aim of this article was to address how SCCs can increase their athletes assuming leadership responsibilities during strength and conditioning training sessions. Often, the development of leadership 298 behaviors is viewed as a by-product of participating in sport (33). However, the development of 299 leadership behaviors, as with most behaviors, takes education, and opportunities for practice (5). Although, there are usually a limited number of formal leadership roles on a sports team, there are a 301 plethora of informal leadership roles and opportunities available (10), especially within strength and 302 conditioning training sessions. The more athletes on a team are demonstrating leadership behaviors, 303 the greater their team cohesion and performance (5). Although a single transformational leadership 304 behavior was highlighted for each example above, it is worth noting that these transformational 305 behaviors can occur in combination; such as giving praise before giving technical feedback, followed by a demonstration of the appropriate exercise technique. Although, these transformational behaviors can

307 go together, the daily opportunities presented broke this complexity down into individual, component

308 behaviors. Therefore, those daily exercises for building each of the individual transformational

309 leadership behaviors are examples of initial learning opportunities for athletes. The rotating opportunities were presented with the transformational leadership behavior most emphasized during 
311 that experience, though other transformational leadership behaviors would also be used by athletes to

312 different degrees. By explicitly teaching and incorporating transformational leadership behavior practice

313 opportunities into the structure of training sessions, SCCs can start to have more athletes as leaders

314 during training. 


\section{References}

316 1. Bandura, A and Cervone, D. Self-Evaluative and Self-Efficacy Mechanisms Governing the

317 Motivational Effects of Goal Systems. J Pers Soc Psychol 45: 1017-1028, 1983.

318 2. Bass, BM, and Bass, RR. Transformational Leadership. In: The Bass handbook of Leadership:

319 theory, research, and managerial applications. New York, NY: Free Press, 2008. pp. 618-648.

$320 \quad 3 . \quad$ Bass, B. Leadership and performance beyond expectation. New York, NY: Free Press, 1985.

321 4. Bass, BM. Two Decades of Research and Development in Transformational Leadership. Eur J

$322 \quad$ Work Organ Psychol 8: 9-32, 1999.

323 5. Bean, CN and Forneris, T. Is Life Skill Development a By-Product of Sport Participation?

324 Perceptions of Youth Sport Coaches. J Appl Sport Psychol 29: 234-250, 2017.

325 6. Callow, N, Smith, MJ, Hardy, L, Arthur, CA, and Hardy, J. Measurement of transformational leadership and its relationship with team cohesion and performance level. J App/ Sport Psychol 21: 395-412, 2009.

328 7. Charbonneau, D, Barling, J, and Kelloway, EK. Transformational Leadership and Sports Performance: The Mediating Role of Intrinsic Motivation. J App/ Soc Psychol 31: 1521-1534, 2001.

8. Chelladurai, P and Carron, A V. Athletic Maturity and Preferred Leadership. J Sport Psychol 5: 371-380, 1983.

9. Chelladurai, P and Riemer, HA. Measurement of leadership in sport. In: Advances in sport and exercise pscyhology measurement. Duda, JL, ed. Morgantown, WV: Fitness Information Technology, 1998. pp. 227-253.

336 10. Crozier, AJ, Loughead, TM, and Munroe-Chandler, KJ. Examining the Benefits of Athlete Leaders in Sport. J Sport Behav 36, 2013.

338 11. Dorgo, S. Unfolding the Practical Knowledge of an Expert Strength and Conditioning Coach. Int J 
Sport Sci Coach 4: 17-30, 2009.

340 12. Feltz, DL, Short, SE, and Sullivan, PJ. Self-efficacy in sport. Champaign, IL: Human Kinetics, 2008.

341 13. Fitts, PA. Human Performance. Belmont, CA: Brooks/Cole, 1967.

342 14. Gallo, GJ, De Marco, GM, and De Marco Jr., GM. Self-assessment and modification of a division I

343 strength and conditioning coach's instructional behavior. J Strength Cond Res 22: 1228-1235,

3442008.

345 15. Gilbert, WD and Baldis, MW. Becoming an Effective Strength and Conditioning Coach. Strength

$346 \quad$ Cond J 36: 28-34, 2014.

347 16. Grant, MA, Dorgo, S, and Griffin, M. Professional Development in Strength and Conditioning

$348 \quad$ Coaching Through Informal Mentorship : A Practical Pedagogical Guide for Practitioners. Strength

$349 \quad$ Cond J 36: 63-69, 2014.

350 17. Grant, M and Dorgo, S. Developing Expertise in Strength and Conditioning Coaching. Strength

$351 \quad$ Cond J 36: 9-15, 2014.

352 18. Handcock, P and Cassidy, T. Reflective Practice for Rugby Union Strength and Conditioning

$353 \quad$ Coaches. Strength Cond J 36: 41-45, 2014.

354 19. Holmes, RM, Mcneil, M, and Adorna, P. Student Athletes' Perceptions of Formal and Informal

355 Team Leaders. J Sport Behav 33, 2010.

356 20. Horn, TS. Coaching effectiveness in the sports domain. In: Advances in sport psychology. Horn,

357 TS, ed. . Champaign, IL: Human Kinetics, pp. 309-354, 2002.

358 21. Jowett, S. Coaching effectiveness: the coach-athlete relationship at its heart. Curr. Opin. Psychol.

$359 \quad 16: 154-158,2017$.

360 22. Kuklick, CR and Gearity, BT. A Review of Reflective Practice and Its Application for the Football

361 Strength and Conditioning Coach. Strength Cond J 37: 43-51, 2015.

362 23. Loughead, TM, Hardy, J, Eys, MA. The Nature of Athlete Leadership. J Sport Behav Jun 29: 142- 
158, 2006.

364 24. Massey, CD, Maneval, MW, Phillips, J, Vincent, J, White, G, and Zoeller, B. An Analysis of Teaching and Coaching Behaviors of Elite Strength and Conditioning Coaches. J Strength Cond Res 16: 456460, 2002.

367 25. Moore, EWG. Strength Training and Sport Psychology. In: Oxford Research Encyclopedia of 368 Psychology. Braddick, O, ed. . New York, NY: Oxford University Press, pp. 1-31, 2017.

369 26. Neubert, MJ. Too Much of a Good Thing or the more the Merrier? Small Gr Res 30: 635-646, $370 \quad 1999$.

371 27. Neubert, MJ. Too Much of a Good Thing or the more the Merrier?: Exploring the Dispersion and Gender Composition of Informal Leadership in Manufacturing Teams. Small Gr Res 30: 635-646, 1999.

374 28. Newland, A, Newton, M, Podlog, L, Legg, WE, and Tanner, P. Exploring the nature of 375 transformational leadership in sports: a phenomenological examination with female athletes. Qual Res Sport Exerc Heal 7: 663-687, 2015.

377 29. Northouse, PG. Leadership: Theory and practice. 2nd ed. Thousand Oaks, CA, 2001.

378 30. Rudi, M and Booker, R. "Managing" the coaching environment to enhance performance. Strength Cond J 20: 50-56, 1998.

380 31. Schunk, DH. Self-efficacy, motivation, and performance. J App/ Sport Psychol 7: 112-137, 1995.

381 32. Smith, RE, Smoll, FL, and Curtis, B. Coach Effectiveness Training: A Cognitive-Behavioral Approach 382 to Enhancing Relationship Skills in Youth Sport Coaches. J Sport Psychol 1: 59-75, 1979.

383 33. Voight, M. Leadership Education and Development for Strength and Conditioning Professionals 384 and Team Leaders. Strength Cond J 36: 52-62, 2014.

385 34. Wise, JB, Posner, AE, and Walker, GL. Verbal messages strength bench press efficacy. J Strength 
387 35. Yukl, G. Managerial Leadership: A Review of Theory and Research. J Manage 15: 251-289, 1989.

' In addition to the references above, for SCCs interested in learning more about transformational leadership and how to lead in more transformational ways, we recommend the following resource: Transforming Lives Through Coaching by Aubrey Newland of California State University, Chico. 